\title{
Evaluation of a feasible educational intervention in preventing early childhood caries
}

\section{Marina Sousa AZEVEDO(a) \\ Ana Regina ROMANO(a) \\ Marcos Britto CORREA $^{(b)}$ \\ Iná da Silva dos SANTOS(c) \\ Maximiliano Sérgio $\mathrm{CENCI}^{(\mathrm{b})}$}

(a) Universidade Federal de Pelotas - UFPel, Post-graduate Program in Dentistry, Department of Social and Preventive Dentistry, Pelotas, RS, Brazil.

(b) Universidade Federal de Pelotas - UFPel, Post-graduate Program in Dentistry, Department of Operative Dentistry, Pelotas, RS, Brazil.

(c) Universidade Federal de Pelotas - UFPel, Post-graduate Program in Epidemiology, Pelotas, RS, Brazil.

Declaration of Interests: The authors certify that they have no commercial or associative interest that represents a conflict of interest in connection with the manuscript.

Corresponding Author:

Marina Sousa Azevedo

E-mail: marinasazevedo@hotmail.com

DOI: 10.1590/1807-3107BOR-2015.vol29.0089

Submitted: Aug 28, 2014

Accepted for publication: Mar 30, 2015

Last revision: Jun 09, 2015

\begin{abstract}
Early childhood caries (ECC) in the primary dentition of preschoolers remains high. Young children have limited access to oral healthcare, and oral health education (OHE) measures can be a valuable tool to prevent caries in this population. The aim of this study was to evaluate the impact of an early educational intervention on ECC prevention. The study group (SG) comprised 271 children aged 0-12 months and their mothers, who attended 12 selected public health centers (PHC). The SG received oral health instructions from a pamphlet and by verbal explanation of some topics. One year later, a similar sample of children from another 12 PHCs were selected to serve as the control ( $C G ; n=251)$. The children were examined to determine their caries status: decayed = cavitated and/or white spot lesion (maxillary anterior surface); missing; and filled surface index $>0$. There was a one-year follow-up. Socioeconomic and demographic information was collected. Logistic regression was used to estimate the effects of the educational intervention on the ECC odds. A sample of 445 (SG $=194$ and $C G=251$ ) children remained to the end of the study and were examined. The prevalence of caries was $12.9 \%$ in the SG and $17.9 \%$ in the CG. The odds of caries were $80 \%$ higher in the CG than in the SG $(p=0.037)$. The strategy of providing OHE from a pamphlet and with a brief verbal instruction to mothers during their child's first year of life can constitute a valuable tool for ECC prevention.
\end{abstract}

Keywords: Dental Caries; Health Education, Dental; Preventive Dentistry.

\section{Introduction}

Several studies have shown evidence of a marked reduction in the incidence of caries worldwide. ${ }^{1,2}$ However, the prevalence of early childhood caries (ECC) in preschoolers remains high, with no substantial sign of improvement. ${ }^{3}$

ECC has debilitating effects on children's development, speech, general health, and self-esteem, and hence on their overall quality of life. ${ }^{4,5}$ Young children have limited access to oral healthcare, ${ }^{6}$ and the cost of ECC treatment is high, since it may involve early tooth extraction and extensive restoration. ${ }^{78}$ Thus, preventive strategies for ECC play an important role, since they are cost-saving, compared with surgical treatment. ${ }^{9}$

Although a certain number of children benefit from preventive measures against caries ${ }_{,}^{10}$ such as water fluoridation programs and fluoride 
brushing, educational interventions (EI) could target preschool children more effectively, and broaden the population range. In developing countries where healthcare spending must be distributed rationally, EI could aid in the prevention of ECC. Moreover, the provision of such interventions by a trained general health staff with no dental background could reach a larger number of children at a very low cost. ${ }^{11}$

Evidence of the effectiveness of oral health education (OHE) remains controversial, and few high-quality studies assessing this issue have been published. ${ }^{12}$ Moreover, since oral health behavior is established in very early childhood, parents-especially mothers-are dominant role models for their children. ${ }^{13}$ In this context, the need for EI directed at mothers is warranted.

The evaluation of oral health promotion measures is a complex and difficult task that has been underfunded and generally neglected. ${ }^{14}$ Thus, the aim of this study was to evaluate the impact of $\mathrm{OHE}$ through a pamphlet and verbal explanation on ECC prevention. The study hypothesis was that the providing of OHE to mother-child pairs during the first year of the child's life would prevent against ECC.

\section{Methodology}

\section{Participants and study design}

This quasi-experimental study was carried out in Pelotas, a city in southern Brazil with a 93\% urban population. ${ }^{15}$ The local ethics committee approved the study protocol (no. 164/2010) and all mothers provided written informed consent. The study group (SG) comprised predentate infants aged 0-12 months, attending public health centers (PHCs) on National Children's Vaccination Day in 2010. Children with one or more erupted teeth (as reported by mothers) and those living outside of Pelotas, unaccompanied by mothers, and/or having systemic diseases were excluded.

In Brazil, child vaccinations are performed widely in PHCs, regardless of a family's socioeconomic status. Half $(n=12)$ of all the PHCs that fulfilled the inclusion criteria (urban location and facilities allowing dental examination) were selected as study centers. A simple randomization method was used to select a study cluster (PHC), using a computer-generated list of random numbers.

The CG group chosen one year later represented the comparison group. A similar sample of children of the same age was selected from another half of the PHCs, not serving as study centers $(n=12)$, on National Children's Vaccination Day in 2011. Children living outside of Pelotas, unaccompanied by mothers, and/or having systemic diseases were excluded. This sample served as the control group (CG).

Mothers of eligible children were invited to participate in the survey in order of arrival at the respective PHC, regardless of sex and social background. On the vaccination day in 2010, after the SG children were vaccinated, their mothers were interviewed and received OHE. One year later (2011), the children from the same SG were examined at the same PHC on vaccination day. On this same day in 2011, the CG group was selected from another 12 PHCs, with a similar sample of SG children. Also on this day, the mothers of the CG were interviewed and received OHE, and the children were examined (Figure).

The children from both groups received the dental care normally offered at the PHCs. However, the city had no specific oral health program directed at this age group up until 2012; nevertheless, the children could seek dental assistance at the PHCs by spontaneous demand.

Sample size calculation was based on the detection of a smaller proportion of children with caries in dental enamel (from $26 \%$ to $14 \%$ ). This reduction was based on a previous study conducted by Mohebbi et al. ${ }^{11}$ A sample size of 21 children from each PHC was determined as having $>80 \%$ power for the detection of caries reduction, based on the assumption that the intraclass correlation coefficient was 0.03 , totaling a final sample of 504 children

\section{Interviews}

Trained graduate and undergraduate dental students ( $n=12)$ carried out face-to-face interviews with mothers from both groups. The students read the questionnaire and instruction manual, and conducted simulated interviews in two training sessions (4 h each). Some questions from a structured 


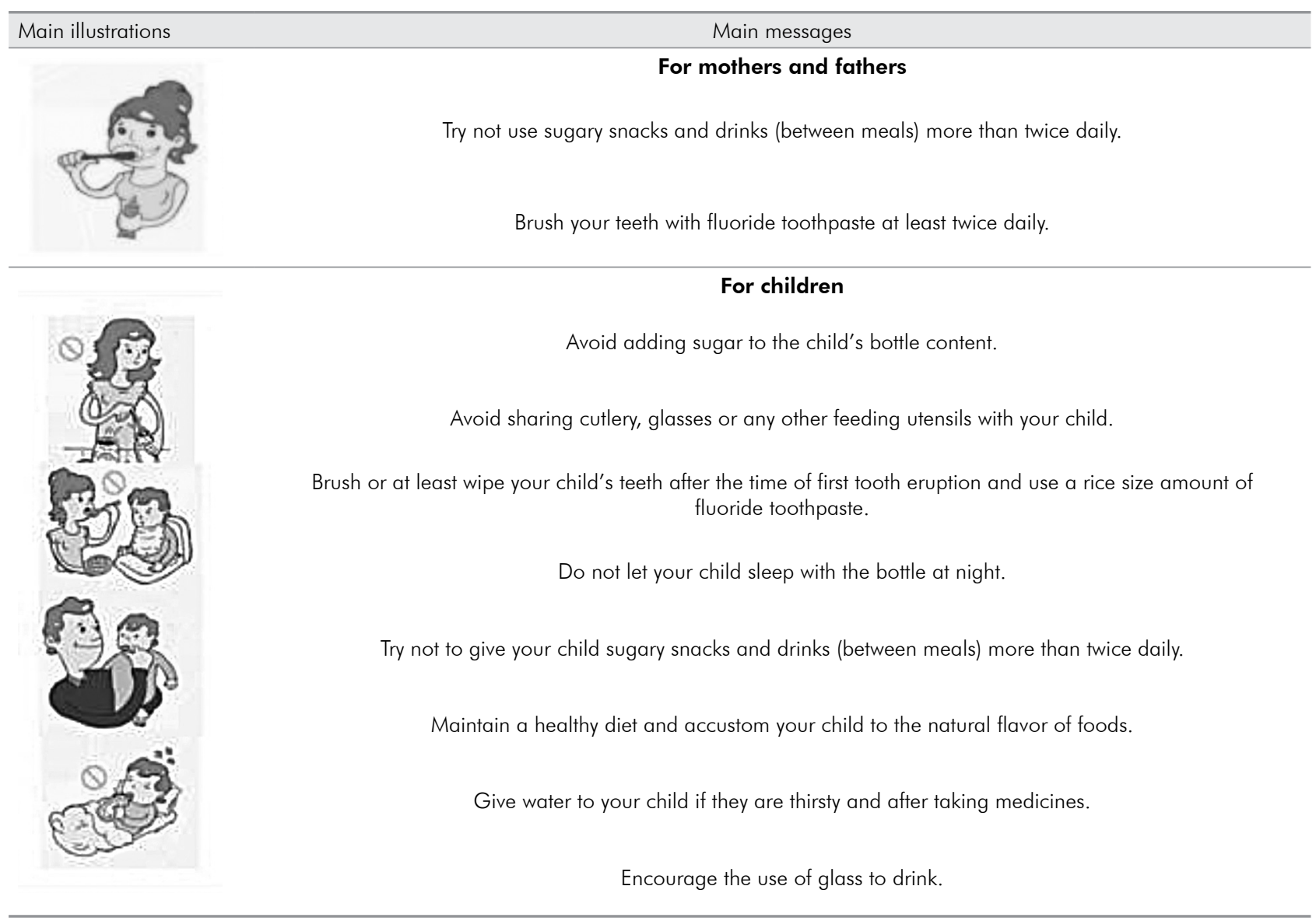

Figure. The main messages and illustrations of the pamphlet used to prevent early childhood caries.

questionnaire pretested in previous studies were used to elicit socioeconomic and demographic information. ${ }^{16,17}$ Family income was collected as continuous data and then converted to Brazilian minimum wages (BMW) (US\$ 275). The monthly wages of all economically active family members were categorized in quartiles. The maternal formal educational level was dichotomized as $\leq 8$ or $>8$ years of schooling. Information about the child's sex and mother's age at the time of the child's birth was also collected.

\section{Oral health education}

In 2010, during Children's Vaccination Day, mothers of the children in the SG each received a pamphlet created specifically for this study, and covering the main topics related to ECC prevention (16 items), together with verbal oral health instructions provided by graduate and undergraduate dental students, covering 3 previously selected items from the pamphlet.

The students were trained $(n=12)$ to follow a standardized protocol to convey the oral health instructions, and received a brief step-by-step manual to help them implement the instructed measures. The OHE session was conducted after the interview, lasting no more than 5 minutes.

The main topics covered by the pamphlet were oral bacteria and their transmission pathways, oral hygiene (for mothers and children), and appropriate dietary habits, such as avoiding both sugar intake (for mothers and children) and sleeping with a bottle at night. The pamphlet was in Portuguese and used simple language. A professional designer developed its visual content, using attractive and cheerful colors and illustrations to capture the mothers' attention (Figure). The original pamphlet is available upon request from the corresponding author. Mothers of 
children in the CG received the pamphlet and oral instructions after completing the study in 2011.

\section{Clinical examination}

Children in both groups underwent a clinical examination at the PHCs on National Children's Vaccination Day in 2011, at the age of 12-24 months. No clinical examination was performed in 2010, because the children were edentulous at the time.

The examination team comprised 12 dentists and advanced dental students blinded to the assignment of the children's group. All examiners were calibrated and completed a $4-\mathrm{h}$ theoretical and training session. In addition, 10 children that were not part of the main sample were examined by the 12 team members and one gold-standard examiner with previous experience in epidemiological studies. The kappa statistic was used to test inter- and intraexaminer reliability; the values ranged from 0.75 to $0.92($ mean $=0.83)$ and 0.86 to 0.97 (mean $=0.93$ ), respectively.

Clinical examinations were performed at the dental offices of the PHCs, under artificial light. Before the examination, the children's teeth were cleaned with gauze and dried with compressed air. Each dental surface in the mouth was then inspected for dentinal caries. ${ }^{18}$ Only the maxillary anterior teeth were inspected for white spot lesions, ${ }^{11}$ because ECC usually starts at the cervical third of upper anterior teeth, and because moisture could be best controlled in this location. White lesions were defined as any sign of whitish opaque (chalky) coloration close to the gingival margin that demonstrated roughness when the probe was moved gently across the surface. ${ }^{19}$ All teeth visible in the mouth were recorded as present, and the number of teeth was calculated for each child. Children with at least one surface affected by caries (decayed: cavitated and/or non-cavitated for the maxillary anterior surface; missing; and filled surface index $>0$ ) were considered as having ECC.

\section{Statistical analysis}

The data were analyzed using Stata software version 11.0 (Stata Corp., College Station, USA). The chi-squared test was used to assess differences in the frequencies of socioeconomic and demographic variables between the SG and CG.
Logistic regression was used to estimate the odds ratios (ORs) and 95\% confidence intervals (CIs) for dental caries in the SG and CG, adjusting for the number of teeth (in tertiles) and the child's age, determinants that could alter estimates of the effect of the intervention on ECC. ${ }^{20}$ ORs were not adjusted for demographic variables (maternal age at child's birth, child's sex) or socioeconomic variables (maternal education, family income), given the lack of evidence for an imbalance between the SG and CG in these variables. ${ }^{20}$ Multilevel regression analysis using a mixed-effects model was conducted to consider the effect of participation at different PHCs. Variance due to PHC (0.12; 95\%CI, 0.01-1.29) was not significant, and a likelihood ratio test showed no difference between the multilevel and ordinary logistic regression models $(p=0.15)$. All analyses were two-tailed, with a significance level of $\alpha=0.05$.

\section{Results}

In 2010, 271 children were recruited to the SG. After a year (2011), 194 children returned to the same PHC and were examined. In the CG, 251 children were recruited to make the comparison, all of which were examined (total, $n=445$ ). Participants in the SG and CG were comparable in terms of sex $(p=0.45)$, maternal age at child's birth $(p=0.10)$, family income $(p=0.17)$, and maternal educational level $(p=0.41)$ (Table 1). There is statistical difference between the groups regarding child's age $(p<0.001)$ and number of teeth $(p=0.001)$. The proportion of children having dental caries (enamel and dentine) was 12.9\% among the SG, and $17.9 \%$ among the CG. In regard to dentine caries, the proportion of children was 1.5\% among the SG and $2.4 \%$ among the CG, and in regard to white spot lesions, it was $11.4 \%$ among the SG and $16.7 \%$ among the CG.

After adjustment, the multivariate analysis showed that the children in the SG had significantly fewer carious lesions than those in the CG ( $p=0.037)$. The odds of dental caries were $80 \%$ greater in the CG than in the SG (OR, 1.8; 95\%CI, 1.04-3.16), after adjustment for the confounding effect of number of teeth and child's age (Table 2). No adverse effects of the intervention were noted. 
Table 1. Distribution of the participants' characteristics in the study and the control groups. Pelotas, Brazil, 2011 ( $n=445)$.

\begin{tabular}{|c|c|c|c|}
\hline Characteristics & $\begin{array}{c}\text { Study } \\
(\mathrm{n}=194)\end{array}$ & $\begin{array}{c}\text { Control } \\
(n=251)\end{array}$ & $p$-value* \\
\hline Sex, boys: n (\%) & $100(51.8)$ & $139(55.4)$ & 0.45 \\
\hline \multicolumn{4}{|c|}{ Maternal age at child's birth: $\mathrm{n}(\%)$} \\
\hline$\geq 31$ years & $46(23.7)$ & $61(24.6)$ & 0.10 \\
\hline $21-30$ years & $114(58.7)$ & $124(50.0)$ & \\
\hline$\leq 20$ years & $24(17.5)$ & $63(25.4)$ & \\
\hline \multicolumn{4}{|l|}{ Family income (quartile): n (\%) } \\
\hline$\leq 1 \mathrm{BMW}^{* *}$ & $54(29.8)$ & $67(26.7)$ & 0.17 \\
\hline 1.1-1.7 BMW & $38(21.0)$ & $62(24.7)$ & \\
\hline 1.8-2.8 BMW & $54(29.8)$ & $57(22.7)$ & \\
\hline$\geq 2.9 \mathrm{BMW}$ & $35(19.3)$ & $65(25.9)$ & \\
\hline \multicolumn{4}{|l|}{ Mother's educational level: n (\%) } \\
\hline$\leq 8$ years & $107(55.4)$ & $149(59.4)$ & 0.41 \\
\hline$>8$ years & $86(45.6)$ & $102(40.6)$ & \\
\hline Child's age (tertile): n (\%) & & & $<0.001$ \\
\hline $12-14$ months & $66(35.1)$ & $125(50.0)$ & \\
\hline $15-16$ months & $55(29.3)$ & $75(30.0)$ & \\
\hline 17-23 months & $67(35.6)$ & $50(20.0)$ & \\
\hline Number of teeth (tertile): $\mathrm{n}(\%)$ & & & 0.001 \\
\hline 1-8 teeth & $80(41.2)$ & $139(55.4)$ & \\
\hline $9-11$ teeth & $36(18.6)$ & 51 (20.3) & \\
\hline 12-18 teeth & $78(40.2)$ & $61(24.3)$ & \\
\hline
\end{tabular}

${ }^{*}$ Chi-square two-tailed P-value.

**1 BMW (Brazilian Minimum Wage) $=$ U\$275.00/month.

\section{Discussion}

The findings of this study indicate that an EI to prevent against ECC, targeting mothers of children in the first year of life, may reduce dental caries. Direct comparison of these results with those of previous studies is difficult, since assessments of the effectiveness of EIs in preventing against ECC have been based on wide-ranging educational strategies. Anticipatory guidance, counseling, and providing information by pamphlets, mail, videotape, and/or telephone have been used.11,20,21,22,23 In addition, interventions have been conducted by home visits or mail or telephone $\mathrm{e}^{20,21,23}$, and also at health units (public hospitals and PHCs). ${ }^{11,22}$

The effect of an EI similar to that used in this study was evaluated in a randomized trial cluster conducted in Iran..$^{10}$ The 6-month intervention targeted 12-to-15-month-old children with mothers, in two intervention groups. One received information from a pamphlet plus oral health instructions, and the other received not only pamphlets and instructions, but also reminders by telephone. The study findings were similar to ours, and the authors recommended the widespread provision of an $\mathrm{OHE}$ with pamphlets, as a feasible means of preventing against ECC. ${ }^{11}$

It is important to highlight that Pelotas had no specific oral health program directed at this age

Table 2. Odds ratio for dental caries (white spots and dentine) between the study group $(\mathrm{n}=194)$ and the control group $(\mathrm{n}=251)$. Pelotas, Brazil, 2011 ( $\mathrm{n}=445$ ).

\begin{tabular}{|c|c|c|c|c|c|c|c|c|}
\hline Variables & & Dental caries N (\%) & OR & $(95 \% \mathrm{Cl})^{*}$ & p-value* & OR & $(95 \% \mathrm{Cl})^{* *}$ & $\mathrm{p}$-value ${ }^{* *}$ \\
\hline \multicolumn{9}{|l|}{ Groups } \\
\hline & Intervention & $25(12.9)$ & 1.0 & & 0.15 & 1.0 & & 0.037 \\
\hline & Control & 45 (17.9) & 1.5 & $(0.87-2.51)$ & & 1.8 & $(1.04-3.16)$ & \\
\hline \multicolumn{9}{|c|}{ Number of teeth } \\
\hline & $1-8$ & $19(8.7)$ & 1.0 & & $<0.001$ & 1.0 & & 0.004 \\
\hline & $9-11$ & $19(21.8)$ & 2.9 & $(1.47-5.88)$ & & 2.6 & $(1.26-5.55)$ & \\
\hline & $12-18$ & $33(23.0)$ & 3.1 & $(1.70-5.82)$ & & 3.0 & $(1.45-6.37)$ & \\
\hline & & & & & & & & 0.338 \\
\hline \multicolumn{5}{|c|}{ Child's age (months) } & 0.005 & & & \\
\hline & $12-14$ & $139(63.5)$ & 1.0 & & & 1.0 & & \\
\hline & $15-16$ & $51(63.6)$ & 1.9 & $(1.02-3.67)$ & & 1.4 & $(0.70-2.80)$ & \\
\hline & $17-23$ & $61(43.9)$ & 2.4 & $(1.29-4.61)$ & & 1.4 & $(0.65-3.03)$ & \\
\hline
\end{tabular}

OR: odds ratio; $\mathrm{Cl}$ : confidence interval.

* Unadjusted crude univariate analysis.

${ }^{* *}$ Adjusted for number of teeth and child's age. 
group up until 2012. However, we cannot exclude the possibility that mothers may have received some caries-prevention-related oral health instruction from health professionals in private practice or other dental/health services. This information should be borne in mind in interpreting the results.

Although printed material has widely been used as an educational tool, and pamphlets have proved effective in broadening knowledge and changing attitudes and behaviors, ${ }^{24}$ the average literacy rates in the populations most affected by caries in Brazil and other developing countries could compromise the effectiveness of this type of intervention. However, even under these conditions, our results showed that the use of a pamphlet improved oral health conditions in the SG. Since many cities in Brazil and other countries lack wide-reaching OHE programs, the use of simple tools such as printed educational material with brief verbal instructions could be an effective alternative to preventing against ECC.

Other studies have also reported good results for EIs, in terms of ECC reduction; ;1,22,25 however, most of these studies called for intensive regular visits, regular interventions, or direct involvement by additional staff. Thus, the notion of regularly delivered information may be an important element in securing the success of an intervention. Nonetheless, the impact of associated costs on the overall cost-effectiveness of the intervention should be taken into account. ${ }^{22}$ A randomized trial demonstrated that outcomes of a pamphlet-based intervention were better when mothers received additional motivation in the form of telephone reminders. ${ }^{11}$

Intervention costs were not calculated, but the low cost of such approaches may represent an advantage. Nevertheless, we can assume that the overall cost of this intervention is lower than many other approaches, given the low cost per pamphlet (US\$ 0.36). A dental health education program designed to prevent against ECC by home visits proved to have better benefit-cost and cost-effectiveness ratios than other preventive programs, such as those using fissure sealant and slow-release fluoride devices. ${ }^{26}$

Although staff members with a dental background distributed the pamphlet and provided verbal oral health instruction, other trained professionals working in health centers could deliver the intervention. This intervention could also be adapted to reach children who do not attend dental health services, given that the proportion of individuals in Brazil who had never seen the dentist was found to be significantly higher at 6 years of age $(71.5 \%)$ than in older age groups. ${ }^{17}$

Although the incidence of dental caries was lower in the SG than in the CG, it remained high $(12.9 \%)$, suggesting that the intervention alone was not enough to change all mothers' behavior. Human behavior is extremely complex, and oral health behavior is largely influenced by social determinants. ${ }^{27}$ Thus, we cannot assume that all individuals who acquire the relevant knowledge and skills will alter their behavior to maintain good oral health.

In this study, the definition of caries included non-cavitated lesions, which are more prevalent than cavitated carious lesions in the primary teeth of children aged 6-18 months, and which can provide more useful data on the caries process in primary teeth. ${ }^{28}$ Only maxillary anterior teeth were examined for non-cavitated lesions, because dental caries initially start in this region ${ }^{29}$ and saliva control is best monitored also in this area. ${ }^{30}$ Additionally, since the ECC outcome was dichotomized as "presence" or "absence" of caries lesions, we can assume that, even without checking the white spots on the other teeth surfaces, practically no child was misdiagnosed.

Although the background characteristics of children in the SG and CG were comparable, some limitations of this research design should be pointed out. Loss to follow-up in the SG may have biased the results. People dropping out of the study group may feel that they let down the intervention staff because they had "poor" results (e.g.: many carious teeth); thus children who did not return may have had worse prognoses. However, in Brazil, according to the Statute of the Child, the childhood vaccination schedule is mandatory and all children who returned to the study PHCs underwent the examination without refusal. Children from the SG not accounted for in the follow-up may have gone to another PHC not initially selected, for reasons other than poor results, such as their moving to another neighborhood or city, which is quite common among young couples. 
In any case, losses in the CG could not be measured or analyzed comparatively, because no baseline data were recorded for this group.

Another limitation is the possibility of children having teeth at their first appointment. One of the reasons for excluding a child was the criterion of having one or more erupted teeth (as reported by mothers). The primary teeth that usually come in first are the lower central incisors, located in the middle and front of the lower jaw, thereby being easily identified by mothers. Although the excluded children were not examined, we cannot guarantee that all of the included children did not have erupted teeth; however, we took care to exclude mothers who were not sure if their children did or did not have teeth. In addition, our statistical analysis was adjusted by number of teeth, thus minimizing the possibility of bias due to study design.

Any quasi-experimental study design has known limitations; these designs have some intermediate

\section{References}

1. Gaszynska E, Wierzbicka M, Marczak M, Szatko F. Thirty years of evolution of oral health behaviours and dental caries in urban and rural areas in Poland. Ann Agric Environ Med. 2014;21(3):557-61.

2. Narvai PC, Frazao P, Roncalli AG, Antunes JL. [Dental caries in Brazil: decline, polarization, inequality and social exclusion]. Rev Panam Salud Publica. 2006 Jun;19(6):385-93.

3. Begzati A, Meqa K, Siegenthaler D, Berisha M, Mautsch W. Dental health evaluation of children in kosovo. Eur J Dent. 2011 Jan;5(1):32-9.

4. Davies GN. Early childhood caries--a synopsis. Community Dent Oral Epidemiol. 1998;26(1 Suppl):106-16.

5. Goettems ML, Ardenghi TM, Romano AR, Demarco FF, Torriani DD. Influence of maternal dental anxiety on oral health-related quality of life of preschool children. Qual Life Res. 2011Aug;20(6):951-9.

6. Seale NS, Casamassimo PS. Access to dental care for children in the United States: a survey of general practitioners. J Am Dent Assoc. 2003 Dec;134(12):1630-40.

7. Weinstein P. Public health issues in early childhood caries. Community Dent Oral Epidemiol. 1998;26(1 Suppl):84-90.

8. Tinanoff N, O'Sullivan DM. Early childhood caries: overview and recent findings. Pediatr Dent. 1997 Jan-Feb;19(1):12-6.

9. Ramos-Gomez FJ, Shepard DS. Cost-effectiveness model for prevention of early childhood caries. J Calif Dent Assoc. 1999 Jul;27(7):539-44. level of internal validity. The internal validity is defined as the degree to which observed changes in outcomes can be correctly inferred as caused by an intervention. Alternative explanations for the apparent causal association can be attributed to chance and not to the intervention. ${ }^{31}$ The bias of using a control group one year later was minimized by the multivariate analysis, which was adjusted by number of teeth and child's age.

\section{Conclusions}

Within the limitations of the present study, the results suggest that providing OHE from a pamphlet and by brief verbal instructions to mothers during their child's first year of life can be a valuable tool for preventing against ECC. Well-designed clinical trials are needed to confirm the effects, estimate the cost-effectiveness, determine how to identify mothers who require reinforcement, and assess the long-term sustainability of educational interventions.

10. Marthaler TM. Changes in dental caries 1953-2003. Caries Res. 2004 May-Jun;38(3):173-81.

11. Mohebbi SZ, Virtanen JI, Vahid-Golpayegani M, Vehkalahti MM. A cluster randomised trial of effectiveness of educational intervention in primary health care on early childhood caries. Caries Res. 2009;43(2):110-8.

12. Kay EJ, Locker D. Is dental health education effective? A systematic review of current evidence. Community Dent Oral Epidemiol. 1996 Aug;24(4):231-5.

13. Jones S, Hussey R, Lennon MA. Dental health related behaviours in toddlers in low and high caries areas in $\mathrm{St}$ Helens, north west England. Br Dent J. 1996 Jul 6;181(1):13-7.

14. Watt RG, Harnett R, Daly B, Fuller SS, Kay E, Morgan A, et al. Evaluating oral health promotion: need for quality outcome measures. Community Dent Oral Epidemiol. 2006 Feb;34(1):11-7.

15. Instituto Nacional de Geografia e EStatística [Internet]. Estimativas da população: 2011. Brasília (DF): IBGE; 2011 [cited 2011 Oct 10]. Available from: http://www.ibge.gov.br/ cidadesat/painel/painel.php?codmun $=431440$

16. Barros AJ, Santos IS, Victora CG, Albernaz EP, Domingues MR, Timm IK, et al. The 2004 Pelotas birth cohort: methods and description. Rev Saude Publica. 2006 Jun;40(3):402-13.

17. Franca-Pinto CC, Cenci MS, Correa MB, Romano AR, Peres MA, Peres KG, et al. Association between black stains and dental caries in primary teeth: findings from a Brazilian population-based birth cohort. Caries Res. 2012;46(2):170-6. 
18. World Health Organization. Oral Health Surveys: basic methods. 3rd.. Geneva: WHO; 1997.

19. Nyvad B, Machiulskiene V, Baelum V. Reliability of a new caries diagnostic system differentiating between active and inactive caries lesions. Caries Res. 1999 Jul-Aug;33(4):252-60.

20. Feldens CA, Vítolo MR, Drachler ML. A randomized trial of the effectiveness of home visits in preventing early childhood caries. Community Dent Oral Epidemiol. 2007 Jun;35(3):215-23.

21. Kowash MB, Pinfield A, Smith J, Curzon ME. Effectiveness on oral health of a long-term health education programme for mothers with young children. Br Dent J. 2000 Feb 26;188(4):201-5.

22. Plutzer K, Spencer AJ. Efficacy of an oral health promotion intervention in the prevention of early childhood caries. Community Dent Oral Epidemiol. 2008 Aug;36(4):335-46.

23. Weinstein P, Harrison R, Benton T. Motivating mothers to prevent caries: confirming the beneficial effect of counseling. J Am Dent Assoc. 2006 Jun;137(6):789-93.

24. Paul C, Redman S. A review of the effectiveness of print material in changing health-related knowledge, attitudes and behaviour. Health Promot J Austr. 1997 Aug;7(2):91-9.

25. Feldens CA, Giugliani ER, Duncan BB, Drachler MeL, Vítolo MR. Long-term effectiveness of a nutritional program in reducing early childhood caries: a randomized trial. Community Dent Oral Epidemiol. 2010 Aug;38(4):324-32.
26. Kowash MB, Toumba KJ, Curzon ME. Cost-effectiveness of a long-term dental health education program for the prevention of early childhood caries. Eur Arch Paediatr Dent. 2006 Sep;7(3):130-5.

27. Watt RG. Strategies and approaches in oral disease prevention and health promotion. Bull World Health Organ. 2005 Sep;83(9):711-8.

28. Drury TF, Horowitz AM, Ismail AI, Maertens MP, Rozier RG, Selwitz RH. Diagnosing and reporting early childhood caries for research purposes. A report of a workshop sponsored by the National Institute of Dental and Craniofacial Research, the Health Resources and Services Administration, and the Health Care Financing Administration. J Public Health Dent. 1999 Summer;59(3):192-7.

29. Vachirarojpisan T, Shinada K, Kawaguchi Y, Laungwechakan P, Somkote T, Detsomboonrat P. Early childhood caries in children aged 6-19 months. Community Dent Oral Epidemiol. 2004 Apr;32(2):133-42.

30. Chan SC, Tsai JS, King NM. Feeding and oral hygiene habits of preschool children in Hong Kong and their caregivers' dental knowledge and attitudes. Int J Paediatr Dent. 2002 Sep;12(5):322-31.

31. Shadish WR, Cook TD, Campbell DT. Experimental and quasi-experimental designs for generalized causal inference. Boston: Houghton Mifflin; 2002. 